\title{
Assessment of Concept Mapping Models and Structured Content Models
}

\section{Dr. Mysore Narayanan, Miami University}

DR. MYSORE NARAYANAN obtained his Ph.D. from the University of Liverpool, England in the area of Electrical and Electronic Engineering. He joined Miami University in 1980 and teaches a wide variety of electrical, electronic and mechanical engineering courses. He has been invited to contribute articles to several encyclopedias and has published and presented dozens of papers at local, regional, national and international conferences. He has also designed, developed, organized and chaired several conferences for Miami University and conference sessions for a variety of organizations. He is a senior member of IEEE and is a member of ASME, SIAM, ASEE and AGU. He is actively involved in CELT activities and regularly participates and presents at the Lilly Conference. He has been the recipient of several Faculty Learning Community awards. He is also very active in assessment activities and has presented more than thirty five papers at various Assessment Institutes. His posters in the areas of Assessment, Bloom's Taxonomy and Socratic Inquisition have received widespread acclaim from several scholars in the area of Cognitive Science and Educational Methodologies. He has received the Assessment of Critical Thinking Award twice and is currently working towards incorporating writing assignments that enhance students' critical thinking capabilities. 


\begin{abstract}
A well-designed instructional module ensures that the subject matter content is effectively integrated with the presentation format. In other words, the instructor attempts to blend the presentation and content in theory as well as practice. In reality, the instructor should assume the role of a facilitator and effectively utilize modern technology to experiment on innovative ideas. The ultimate objective is a delivery mechanism that can lead to new classroom instructional strategies.

Researchers are also of the opinion that education in a new learning paradigm will better prepare students for the work ahead of them. Whether it be performance arts like theatre and music, or be it a laboratory setting like physics or biology, student performance can be effectively accentuated by adopting creative instructional lesson plans. Furthermore, many of our educational institutions have tried to move away from emphasizing the establishment of a strong knowledge-base. In this paper the author discusses two models that he has successfully utilized for accentuating student performance. The first is identified as Concept Mapping Model and the second in identified as Structured Content Model.
\end{abstract}

These two models are of particular interest to Ocean Engineering Courses because certain topics and subject matter can be better presented to the students by selective choice of one of these two models. In certain Ocean Engineering foundation courses it is very important to stress and cover the fundamental concepts and one has to utilize Structured Content Model. In upper level courses, however the students may benefit with the use of Concept Mapping Model because strong foundation and important concepts have already been established in lower level, elementary and basic courses.

\title{
Introduction
}

The Concept Mapping Model utilizes the principles of a learning paradigm. (Tagg, 2003). The principle is to select an appropriate learning paradigm approach and preferably categorize and assign the needed information into the various components of that chosen paradigm. A model for knowledge acquisition and content delivery can be suggested however, this is normally accomplished utilizing well established and standardized building blocks of a learning paradigm (Barr and Tagg, 1995).

The Structured Content Model may be chosen as an alternative when the instructor finds that the Concept Mapping Model may not be suitable. Here subject matter content can be created independent of presentation format or delivery methodology. Regardless, this is not completely open ended and is mainly dictated by the educational objectives and course outcomes. The literature supports our intuitive belief that education in a new learning paradigm will prepare students for the work ahead of them (Cox, Grasha and Richlin, 1997). 
The author has previously discussed these ideas in a paper he presented at the 2012 ASEE Annual Conference and Exposition (Narayanan, 2012). This paper is a follow-up or a continuation of the work he presented about seven years ago. Educators must be able to successfully address the needs of the individual by relating their own teaching style to the learning style of the individual (Gregorc and Ward, 1977). Reuben Tozman has discussed the delivery mechanism techniques in his publication (Tozman, 2004) entitled: Another New Paradigm for Instructional Design.

The degree of processing speed, accuracy and retention that an individual is able to accomplish when encountering information depends upon to what extent the medium in which information presented matches his or her learning style (Barbe \& Milone, 1980 \&1981).

It has been a well-established fact that learning is an interactive process that takes place in educational environment established specifically to promote to enhance knowledge in a learning atmosphere (Keefe, 1987). Researchers have actually demonstrated that if one utilizes technology systematically, it may actually help the instructor address perceptual dimensions of learning.

Dr. Walter B. Barbe, a nationally known authority in the fields of reading and learning disabilities has shown that perceptual modality styles provides an indication of an individual's dominant learning mode (Barbe \& Milone, 1980 \& 1981).

The above principles have been discussed in greater detail by the author in his previous ASEE conference proceedings and publications (Narayanan, 2007, 2009 \& 2019). Some of those ideas have been reproduced here as deemed appropriate, for sake of clarity and completeness.

\section{Assessment and the 'ACORN' Model}

The use of $\boldsymbol{A C O R N}$ model suggested by Hawkins and Winter to conquer and mastering change, may offer some helpful hints for the novice professor (Hawkins \& Winter, 1997). These five ideas provide guidelines as to how an instructor can successfully try to implement the Concept Mapping Model or the Structured Content Model in a $21^{\text {st }}$ century classroom.

Action :

It is possible to effectively change things only when a teaching professor actually tries out a new idea. In other words, Creativity is important in the $21^{\text {st }}$ Century. We are teaching Technology Savvy Students. Action needs to be taken to make sure there is constant update always. Instructors should focus on Continuous Quality Improvement. This should be based on looking at chosen Bench-Mark Institutions and try to follow what they have successfully accomplished. 
Communication: Changes are successful only when the new ideas are effectively communicated and implemented. This is facilitated by modern technology whether it be e-mail or world-wide-web or internet or You-tube. In the $21^{\text {st }}$ century the student body is more demanding. In other words, appropriate computer software must be intelligently incorporated into the course curriculum content.

Ownership : $\quad$ Support for change is extremely important and is critical. Only strong commitment for accepting changes demonstrates genuine leadership. Both the instructor and the student should participate effectively to promote change. Instructors always ask the students to take Ownership of Learning. The key is to make sure this really happens. This is accomplished by creating interesting research assignments that are short, yet appropriate to the topic under discussion.

Reflection: $\quad$ Feedback helps towards thoughtful evaluation of the changes implemented. Only reflection can provide a tool for continuous improvement. Feedback must be scrutinized and summarized and used as part of continuous quality improvement. Most instructors do conduct an evaluation of the course at the end of the semester. Additional questions should be included to find out how the students react and reflect to the course delivery methodology.

Nurture : $\quad$ Implemented changes deliver results only when nurtured and promoted with necessary support systems, documentation and infrastructures. This is where the institution can play a major role and provide much needed leadership. The department chair, the dean of the school and the executive vice president or the provost should support and promote new innovative teaching ideas that promote active student learning.

\section{Data Collection}

- The procedure followed by the author is shown in Appendix A.

- One topic was discussed based on the Concept Mapping Model and utilized the principles of a learning paradigm.

- Another topic utilized the Structured Content Model as the delivery mode of instruction. 
- The subject matter discussed was 'Advanced Engineering Mathematics' and the data was collected out over a period of $\mathbf{4}$ semesters. A total of 32 students participated in this study.

- The 32 students were later examined on both the topics. WSU Rubrics were used for purposes of grading and this is shown in Appendix B.

- Grading was holistic and utilized a Likert Scale. Likert Scale is shown in Appendix C.

- Data collected was tabulated on an EXCEL spreadsheet. This is shown in Appendix D.

- A Bar Chart was generated based on the EXCEL data and this is shown in Appendix E.

\section{Data Analysis}

- Observing the bar chart one concludes neither methodology recorded the maximum Likert Scale Score of $\mathbf{5}$.

- This indicates that there is room for improvement in both areas.

- Regardless, it is interesting to note that the Structured Content Model approach recorded a Likert Scale Score of $\mathbf{4}$.

- Students are very much used to traditional methods such as lectures and homework assignments.

- Next, we can see that Concept Mapping Model recorded a modest, yet acceptable Likert Scale Score of 3.

- This indicates that the students are not embracing a non-traditional approach.

\section{Conclusions}

- Based on the "Data Analysis" one can conclude that students like the Structured Content Model a lot. However, there is room for improvement here also.

- Some aspects of Concept Mapping Model could be incorporated here so that the Likert Scale Score improves to 5 . 
- However, one may also argue that the incorporation of Concept Mapping Model could also lower the Likert Scale Score.

- Next, we can conclude that instructors should work hard to promote Concept Mapping Model in the classroom.

- However, one can also conclude that the Structured Content Model is preferred by the preponderance of students.

- Does this mean that the instructors should move in only one direction?

- Or does this mean that instructors should consider utilizing both models as deemed appropriate?

- Regardless, we all should agree that there is lot of room for improvement in both areas. It is indeed a judgement call as to which model is best suited for OMED curriculum, content and courses.

- The author is of the opinion that one should try to incorporate some aspects of Structured Content Model in to the Concept Mapping Model courses so that the Likert Scale Score improves, initially to $\mathbf{4}$ and later on to 5 .

- The author is also of the opinion that one should try to incorporate some aspects of Concept Mapping Model in to the Structured Content Model courses so that the Likert Scale Score improves, initially to $\mathbf{4}$ and later on to $\mathbf{5}$. 


\section{References}

1. Barbe, Walter B.; Milone, Michael N., Jr. (Feb 1981). What We Know about Modality Strengths. Educational Leadership, v38 n5 p378-80

2. Barbe, Walter B.; Milone, Michael N., Jr. (Jan 1980). Modality. Instructor, v89 n6 p44-47

3. Barr, R.B. and Tagg, J. (1995, November/December). From Teaching to Learning: A New Paradigm for Undergraduate Education. Change, 13-24.

4. Cox, M.D., Grasha, A., and Richlin, L. (1997, March). Town meeting. Between Teaching Model and Learning Model : Adapting and Adopting bit by bit. Lilly Atlantic Regional Conference.

5. Gregorc, A. F., \& Ward, H. B. (1977). Implications for learning and teaching: A new definition for individual. NASSP Bulletin, 61, 20-26.

6. Hawkins, P., \& Winter, J. (1997). Mastering change: Learning the lessons of the enterprise in higher education initiative. London: Department for Education and Employment.

7. Narayanan, M. (2007, June), Assessment Of Perceptual Modality Styles Paper presented at 2007 Annual Conference \& Exposition, Honolulu, Hawaii. https://peer.asee.org/1474

8. Narayanan, M. (2009, June), Assessment Based On The Principles Of Theodore Marchese Paper presented at 2009 Annual Conference \& Exposition, Austin, Texas. https://peer.asee.org/5406

9. Narayanan, M. (2012, June), Assessing Instructional Modules that Accentuate Student Performance Paper presented at 2012 ASEE Annual Conference \& Exposition, San Antonio, Texas. https://peer.asee.org/20974

10. Narayanan, M. (2019, June), Runge-Kutta Algorithm and Assessment Paper to be presented at 2019 ASEE Annual Conference \& Exposition, Tampa, Florida.

11. Tozman, Reuben (2004). Another New Paradigm for Instructional Design. Retrieved on November 12, 2005 from

http://www.learningcircuits.org/2004/nov2004/tozman.htm 
APPENDIX A: Procedure Followed by the Author

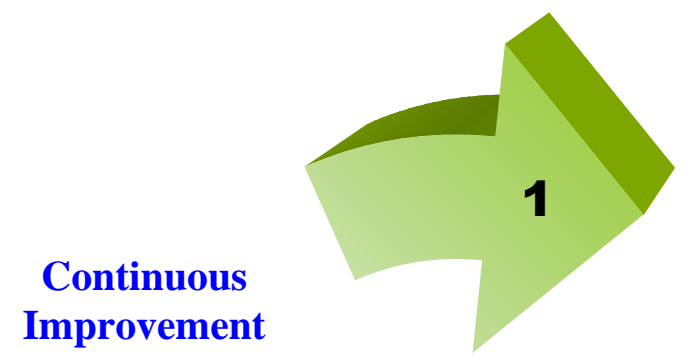

Two Models

Assignment

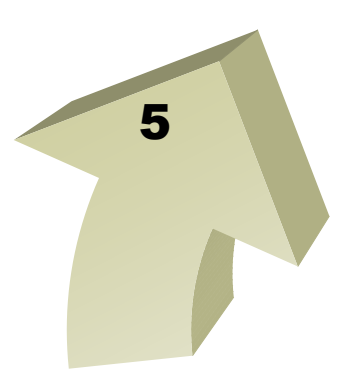

Draw

Conclusions

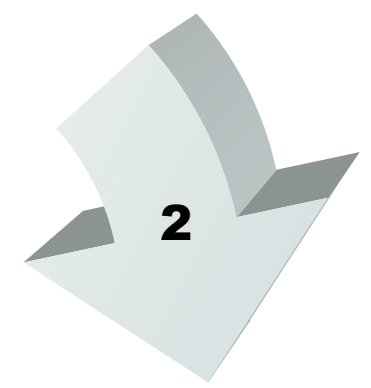

Select

W.S.U.

Rubric

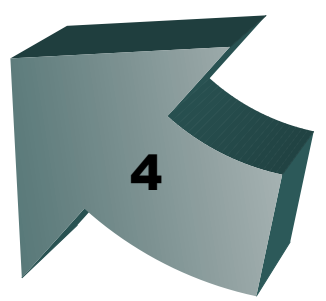

Analyze

Data

Collected

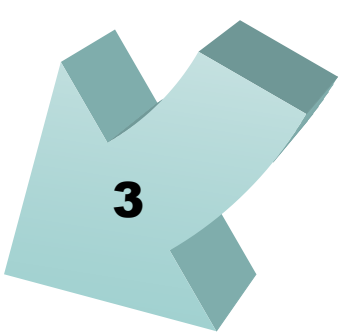




\section{APPENDIX B : Critical Thinking Rubrics (Courtesy of W.S.U., Pullman, WA.) LIKERT SCALE ANALYSIS. 5: Strongly Agree 1: Strongly Disagree}

5

Has demonstrated excellence.

Has provided documentation.

Evidence of critical thinking ability.

Very good performance
Has analyzed important data precisely.

Has answered key questions correctly.

Has addressed problems effectively.

Has evaluated material with proper insight.

Has used deductive reasoning skills.

Has used inductive reasoning skills.

Has employed problem solving skills.

Has discussed consequences of decisions.

Has been consistent with inference.

Data analysis can be improved.

More effort to address key questions.

Need to address problems effectively.

Expand on evaluating material.

Improve deductive reasoning skills.

Improve inductive reasoning skills.

Problem solving skills need honing.

Must discuss consequences of decisions.

Has been vague with inference.

Absence of analytical skills.

Answers questions incorrectly.

Addresses problems superficially.

Lacks documentation.

Inability to evaluate material.

Shows no deductive reasoning power.

Inductive reasoning power non existent.

Poor problem solving skills

Unaware of consequences of decisions.

Unable to draw conclusions.

Source: Critical Thinking Rubric, Washington State University, P.O. Box 644530, Pullman, WA 99164 - 4530 USA.(2005) http://wsuctproject.wsu.edu/ctr.htm The author has utilized this rubric in several of his ASEE publications (2000 - 2019). 


\section{APPENDIX C: Likert Scale Source: http://templatedb.me/pick/}

It should be observed that the data collected are ordinal. This indicates that they have an inherent order or sequence. It must be interpreted carefully. The data is not continuous. Therefore it is not appropriate to create a histogram. Mean values do not have any meaning for interpretation.

Furthermore, Standard Deviation does not convey anything. The data are normally summarized using a median or a mode. The author prefers mode because it is considered to be the most appropriate for this type of data analysis. The data collected are normally displayed in a bar chart.

Four, Five and Six Point Semantic Differential Likert Scale is shown below.

\begin{tabular}{|c|c|c|c|}
\hline $\begin{array}{c}1 \\
\text { Very } \\
\text { Dissatisfied }\end{array}$ & 2 & 3 & 4 \\
Dissatisfied & Satisfied & $\begin{array}{c}\text { Very } \\
\text { Satisfied }\end{array}$ \\
\hline
\end{tabular}

\begin{tabular}{|c|c|c|c|c|}
\hline $\begin{array}{c}1 \\
\text { Very } \\
\text { Dissatisfied }\end{array}$ & 2 & 3 & 4 & 5 \\
Dissatisfied & Neutral & Satisfied & $\begin{array}{c}\text { Very } \\
\text { Satisfied }\end{array}$ \\
\hline
\end{tabular}

\begin{tabular}{|c|c|c|c|c|c|}
\hline 1 & 2 & 3 & 4 & 5 & 6 \\
\hline Extre & Very & Somewhat & Somewhat & Very & Extremely \\
\hline Diss & Dissatisfied & Dissatisfied & Satisfied & Satisfied & Satisfied \\
\hline
\end{tabular}

Reference: http://www.icbl.hw.ac.uk/ltdi/cookbook/info_likert_scale/

Source: Descriptive Techniques: Likert Evaluation Cookbook 2004 
APPENDIX D : EXCEL Spreadsheet data and a sample of grading scheme

\section{Two Models}

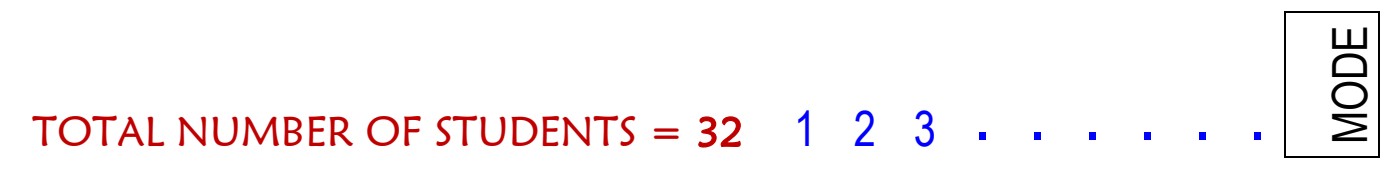

CRITICAL THINKING RUBRIC

RUBRIC COURTESY OF W. S. U.

WASHINGTON STATE UNIVERSITY

PULLMAN, WA. 99164.

LIKERT SCALE WEIGHT

DISTRIBUTION :

1 : Strongly Disagree;

5 : Strongly Agree

\begin{tabular}{|c|c|c|c|c|c|c|c|c|c|}
\hline 1 & Concept Mapping & 3 & 4 & 3 & & & " & & 3 \\
\hline & Structured Content & 3 & 4 & 4 & & & & & 4 \\
\hline
\end{tabular}

Data Collected by Mysore Narayanan. 
APPENDIX E : Bar chart generated based on EXCEL Spreadsheet data

Concept Mapping \& Structured Content Models

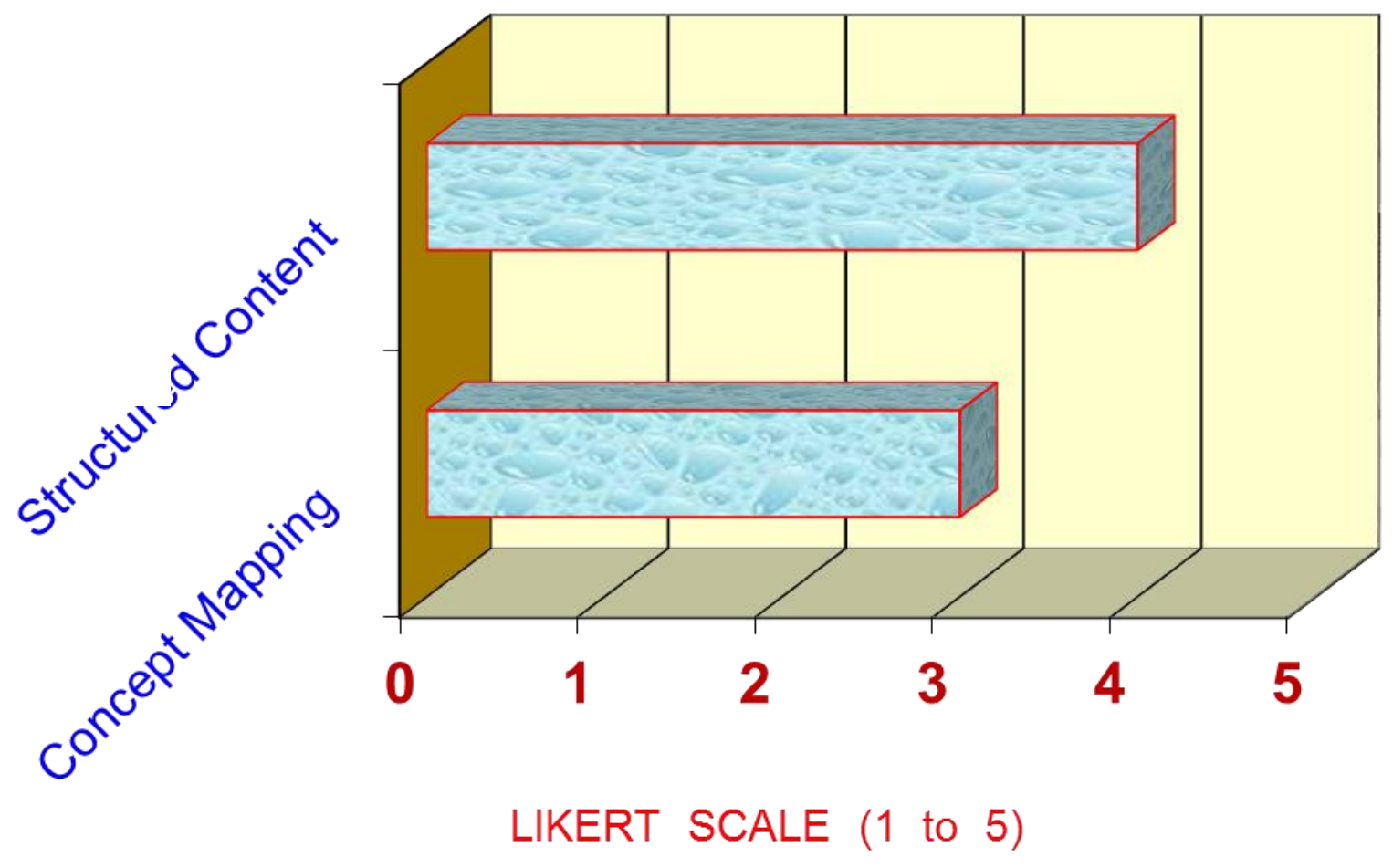

